\title{
Radiation Safety Standards for X-Ray Facilities: Protocol for Plain Radiography D Walker ${ }^{1}$, M Voutchkov $^{2}$, C McKenzie $^{1}$, H Barned $^{3}$
}

\begin{abstract}
Objective: The research focus was to review radiation safety guidelines for x-ray departments.

Methods: Databases such as the Ministry of Health Jamaica library, the American College of Radiology, along with others were consulted. Organizations such as the International Atomic Energy Agency (IAEA), American Association of Physicists in Medicine (AAPM), the World Health Organization (WHO), the United Nations Scientific Committee on the Effects of Atomic Radiation (UNSCEAR) along with others were used as information sources. Publications concerning the topic were also reviewed.

Results: The results showed the different specifications that both the equipment and facility design should meet if the protection of staffs, patients and the public from unnecessary exposure to x-radiation is to be optimized. Quality control tests that should be carried out routinely as well as the standards of performance the unit should maintain while being operated were also presented.
\end{abstract}

Conclusion: Effective building design and planning along with routine quality control test are the most effective ways of ensuring radiation protection in an x-ray facility.

Keywords: Quality control, radiation safety, standards, x-ray

From: ${ }^{1}$ School of Medical Radiation Technology, Faculty of Medical Sciences, University of the West Indies Mona, Kingston, Jamaica. ${ }^{2}$ Department of Physics, Faculty of Science and Technology, University of the West Indies Mona, Kingston, Jamaica. ${ }^{3}$ Department of Anatomy, Pathology and Histology, Faculty of Medical Sciences, University of the West Indies Mona, Kingston, Jamaica.

Correspondence: Mr D Walker, School of Medical Radiation Technology, Faculty of Medical Sciences, University of the West Indies Mona, Kingston, Jamaica. Email: smrt_student2007@yahoo.com 


\section{INTRODUCTION}

Ever since the discovery of x-ray, its application in the field of medicine has grown and expanded tremendously. X-rays however poses health risks (1) and on understanding the dangers, leading world powers came together and established national and international organizations that today regulates the use of x-ray and other sources of radiation in their country and worldwide. Organizations such as the United Nations Scientific Committee on the Effects of Atomic Radiation (UNSCEAR) (founded 1955), the International Atomic Energy Agency (IAEA) (founded 1957) and the American Association of Physicists in Medicine (AAPM) (founded 1979) were soon formed to enforce rules and regulations for the protection of workers and the public. Throughout the years, many nations have developed radiation protection committees, regulations and manuals that aid in the protection of their citizens. The Nuclear Safety and Radiation Protection bill, 2015 was recently signed by the Jamaican government. This is an agreement between the government of Jamaica and the International Atomic Energy Agency that is geared towards the country's corporation with the IAEA and other world bodies in promoting safer radiation practices.

With this agreement, safer radiation practices will be observed industrially as well as in the medical field in accordance with the IAEA standards (1). In 2012 there were 28 radiology departments in Jamaica, with plain x-ray being the most widely used modality (2). This number is expected to have increased since, even though an updated statistics of the number of facilities in the country was not available. As such, this research's aim was to review international safety standards for quality control procedures and facility specifications for Plain X-Ray and make available for Jamaica. 


\section{METHODS}

Detailed literature review of data from several radiation protection agencies such as the American Association of Physicists in Medicine (AAPM), the International Atomic Energy Agency (IAEA), the World Health Organization (WHO) along with others was done. Government documents of several countries addressing regulations concerning the use of ionizing radiation in Diagnostic Radiology such as the United States of America and Canada were included.

\section{RESULTS AND DISCUSSION}

Concerning radiation safety in plain x-ray, the following aspects should be considered; quality control, acceptance tests and the design of the facility.

Quality Control (QC)

Quality control (QC) consists of a series of standardized tests developed to detect changes in x-ray equipment function from its original level of performance (3). The recommended frequency of the different QC tests listed should be as outline in the table.

QC tests, when carried out routinely, allows prompt corrective action to maintain x-ray image quality (3) and for protection from unnecessary ionizing radiation.

For radiation output linearity, for any two consecutive tube current settings, the mAs should not differ by more than 0.10 multiplied by their sum $(7,9)$. The x-ray field in relation to the light field should be so that misalignment does not exceed $2 \%$ of the source to image receptor distance in either dimension of the edges of the light field versus the x-ray field, also, the x-ray central 
beam should be at a 90 degree angle to the grid unless angled intentionally by the radiographer $(5,7)$.

The x-ray unit operates in the range of kilo-voltage, as such the wirings should be inspected for current leakage and electrical safety $(5,7)$. The generator of the x-ray unit should be able to terminate the exposure within the pre-selected time period. Accuracy for preselected times greater than $10 \mathrm{msec}$ should be within $\pm 5 \%$ and for times less than $10 \mathrm{msec} \pm 10 \%$. $(5,7)$ Concerning tube leakage, this should not exceed $1 \mathrm{mGy}$ per hour at $1 \mathrm{~m}$ from the tube $(6,10-11)$. Acceptance tests:

Before an x-ray unit is used to image patients, several tests should be carried out to ensure the unit is operating optimally and possess no radiation or electrical risks to patients, staff and the public. These tests called Acceptance Tests, are to be carried out by a Medical Physicist and may include some of the tests listed previously for quality control along with those listed prior under Acceptance Tests in the preceding table. $(6,9,10-19)$.

Relating to the $\mathrm{x}$-ray unit, the x-ray tube must be secured within the $\mathrm{x}$-ray tube housing. The unit's locking devices should be able to secure the tube in any desired position and orientation. The extension cables must be shock proof, rodent proof, as well as its length should not impede the movement and angulation of the x-ray tube $(6,11,13,14)$. The control panel should be equipped with a warning light that indicates when a radiation exposure is taking place $(6,9,11-13,15)$. The light signal should commence at the beginning of the exposure and remain on for the duration of the exposure. The same applies to audible warning as well. The x-ray unit should have a combination of both light and audible indicators of radiation exposure $(6,9,11-13$, 15). The exposure switch of the unit should be constructed so that irradiation can be terminated manually $(6,9,10,11,15)$. On pressing the exposure switch for irradiation, repeat irradiation 
should not be possible without first release of the exposure switch $(6,9,10,11,15)$. All x-ray units should be equipped with a light beam collimator and the minimum permanent inherent filtration in the useful beam expressed as millimeters of aluminum equivalent at a specified peak tube potential should be permanently marked on the external surface of the x-ray tube $(6,9,10$, $11,15,16)$

In regard to radiation exposure made by the x-ray unit, the accuracy of the loading factors (beam quality and quantity) should not deviate from the selected value by more than $10 \%$ for $\mathrm{kVp}$ and $20 \%$ for mAs $(6,9,16)$. If Automatic Exposure Control (AEC) is used, the variation of optical density in the resultant radiographs should not exceed the value of 0.15 when the x-ray tube voltage is variable and the thickness of the irradiated object is constant, 0.20 when the thickness of the irradiated object is variable and the $\mathrm{x}$-ray tube voltage is constant, 0.20 when both are variable and 0.10 when both are constant $(6,10,16)$.

\section{Radiation protection and $x$-ray room design}

All Imaging Department must be properly planned and radiation protection must be the chief priority of the design (20). The primary aim of radiological protection is to provide an appropriate standard of protection for mankind without unduly limiting the beneficial practices giving rise to radiation exposure (21). The walls of the x-ray room will serve as the main barriers protecting the public from radiation, as such, factors including the maximum $\mathrm{x}$-ray workload of the unit, the occupancy factor of the area being protected, the use factor of the wall and the material that is being used for shielding (building material) must be considered $(6,9,11,14,19)$. Special consideration must be given to the thickness of walls which the $\mathrm{x}$-ray beam will point directly to as well as those separating the dark room from the x-ray room $(6,9,11,19)$.

The equations for calculating barrier thickness includes: 
Primary Barrier: $\quad\left(\mathrm{T}_{\mathrm{pri}}\right) \mathrm{K}=\mathrm{Pd}_{2}{ }^{2} /$ WUT. Secondary Barrier: $\mathrm{T}_{\mathrm{sec}}=\mathrm{Pd}_{1}{ }^{2} \mathrm{~d}_{2}{ }^{2} \mathrm{x} 100 / \mathrm{WT}$

Leakage Barrier: $\quad \mathrm{T}_{\mathrm{L}}=\mathrm{Pd}_{2}{ }^{2} / \mathrm{LtT}$

Where: $\mathbf{T} \mathbf{p r i}(\mathbf{K})$-The Transmission Dose for Primary Radiation or exposure per unit workload at unit distance in $\mathrm{mSv} / \mathrm{mA}$-min or R/mA-min (old unit) at 1 metre, $\mathbf{T}_{\text {sec }}$-The Transmission Dose for Secondary Radiation, $\mathbf{T}_{\mathbf{L}}$-The Transmission Dose for Leakage Radiation. W -Work Load mA.min/week, $\mathbf{U}$-Use Factor, $\mathbf{P}$-Maximum Permissible Dose, T -Occupancy Factor, $\mathbf{t}$-Actual Time of Exposure, $\mathbf{d}_{1}$-Distance between the Focal Spot and the Film, $\mathbf{d}_{2}$-Distance between the Focal Spot and the Wall (19).

The windows in a newly built x-ray department should always be at a height pf $2.1 \mathrm{~m}$ or $7 \mathrm{ft}$ high $(6,14,19)$. For low windows in a renovated building, these should be covered with high lead equivalent material such as bricks or concrete (14). The ceiling of the x-ray room must be strong enough to support the tube weight (using overhead steel railings) and should not be less than $2.5 \mathrm{~m}$ in height $(6,19)$. The ceiling should also provide shielding for floors above $(6,9,11$, 19). As for the floor, it should be strong enough to handle the weight of the x-ray unit as well as provide effective shielding for people below in the event another floor is located below it $(6,9$, $11,19)$.

The x-ray room should be no less than $50 \mathrm{~m}^{2}$ in size as to allow the maneuver of a bed, trolley or wheelchair next to the x-ray table $(6,19)$. The control panel area must be at least $2 \mathrm{~m}$ (6-7ft) from the patient and should be positioned so that the radiographer has visual of both the patient and the entrance door to the $\mathrm{x}$-ray room $(6,10,14,19)$. The protective barrier should be at least $2.1 \mathrm{~m}(7 \mathrm{ft})$ in height and have a viewing window of approximately $1.5 \mathrm{~mm}$ lead equivalence $(11,19)$. 
There should be appropriate overlap of shielding materials especially at joints or discontinuities between walls and doors (11). The number of doors for entry to the x-ray room should be kept at a minimum and be self-closing as to enhance protection (11). The doors should be wide enough to allow easy transport of patients in a wheel chair or on a stretcher and should have built in lead $(11,19)$. The x-ray room should be well ventilated with forced ventilation (air conditioning) for departments located in hot climates $\left(>35^{\circ} \mathrm{C}\right.$ and $>90 \%$ humidity). This will ensure the protection of solid state circuits which make up the unit (19).

The department should have supervised and control area. The control area should be marked with warning signs indicating high radiation area (10). As for the supervised area, radiation dose to workers in this area should be less than $3 / 10$ of the occupational limit (Occupational dose; whole body: $50 \mathrm{mSv} / \mathrm{yr}$, skin: $500 \mathrm{mSv} / \mathrm{yr}$, extremity: $500 \mathrm{mSv} / \mathrm{yr}$, any other organ than the lens of the eye: $500 \mathrm{mSv} / \mathrm{yr}$ and lens of eye: $150 \mathrm{mSv} / \mathrm{yr})(10,19)$.

Radiation warning signs should be posted on all entrance doors of each radiographic room and a warning light placed at either eye level or above the entrance door to each examination room to indicate when exposure is taking place $(6,9,10,19)$.

\section{CONCLUSION}

Effective building design and planning along with routine quality control test are the most effective ways of ensuring radiation protection in an $\mathrm{x}$-ray facility. 


\section{REFERENCES}

1. The Nuclear Safety and Radiation Protection bill, (2015).

2. List of Health Facilities Non-Governmental organizations/community based organization and International Agencies. In: Health Mo, editor. Jamaica 2012.

3. Périard M, Chaloner P. Diagnostic X-Ray Imaging Quality Assurance: An Overview. In: Radiation Protection Bureau Hpb, editor. Canada.

4. QUALITY CONTROL RECOMMENDATIONS FOR DIAGNOSTIC RADIOGRAPHY. Conference of Radiation Control Program Directors, Inc; Frankfort, Kentucky Committee on Quality Assurance in Diagnostic X-ray 2001.

5. Publishing MP. QUALITY CONTROL IN DIAGNOSTIC RADIOLOGY. AAPM REPORT NO 74. 2002.

6. Radiation Protection in Radiology Large Facilities 35 (2008).

7. Guide for Radiation Safety/Quality Assurance Programs in Small Facilities (2004).

8. Quality Assurance and Quality Control of Equipment in Diagnostic Radiology Practice [Internet]. Intech. 2011 [cited 2013].

9. X-ray Equipment in Medical Diagnosis Part A: Recommended Safety Procedures for Installation and Use. In: Branch HEaCS, editor. Canada Health Canada 2000.

10. GUIDANCE NOTES ON RADIATION PROTECTION FOR DIAGNOSTIC RADIOLOGY. In: Health Do, editor. Hong Kong 2004.

11. Safety Code for Medical Diagnostic X-Ray Equipment and Installations, (2001).

12. Radiation Protection Guidance for Diagnostic and Interventional X-Ray Procedures. In: Agency EP, editor. Washington, United States of America 2014. 
13. Holm T. Consumer Guide For The Purchase of X-Ray Equipment. Sweden World Health Organization 2000.

14. Palmer P, Hanson G. DIAGNOSTIC IMAGING IN THE COMMUNITY (A Manual for Clinics and Small Hospitals). In: Organization PH, editor. 2011.

15. Safety Guide for Diagnostic and Interventional Radiology. In: Agency ARPaNS, editor. Australia 2007.

16. Tests to be performed during acceptance and status testing http://oftankonyv.reak.bme.hu/tikiindex.php?page $=$ Tests + to + be + performed + during + acceptance + and + status + testing 2016 [cited 2016].

17. Mahesh M, Boone J. ACR-SPR Practice Guideline for General Radiography. American College of Radiology. 2008.

18. ACR-AAPM-SIIM Technical Standard for Electronic Practice of Medical Imaging American College of Radiology. 2012.

19. Salem D, Abdel-Raham M. Standard Specifications for Basic Diagnostic Radiology Departments. In: Health Mo, editor. Egypt Egypt Swiss Radiology Project; 2011.

20. Agency IAE. Applying radiation safety standards in diagnostic radiology and interventional procedures using X-rays. Safety Report Series. Vienna 2006.

21. Protection ICoR. Recommendations of the International Commission on Radiological Protection ICRP Publication. 103 ed2007. 
Table: Frequency of Quality Control Tests (4-8)

\begin{tabular}{ll}
\hline Frequency of Test & Quality Control Test \\
\hline Daily & Tube Warm Up, Equipment Condition \\
& Assessment, Film Processor Function, Cassette \\
Weekly & Cleaning. \\
& Imaging System Cleanliness, Dark Room \\
Monthly or Quarterly & Cleanliness. \\
& Retake Analysis, View Box Condition, \\
& Collimator Operation, Interlocks, X-Ray Beam \\
annually & and Grid Alignment. \\
& Safelight Testing, Accuracy of Loading \\
& Factors, Radiation Output Linearity and \\
& Reproducibility, X-Ray Beam Filtration and \\
& Collimation, X-Ray Field and Alignment, \\
& Integrity of Protective Equipment. \\
\hline
\end{tabular}




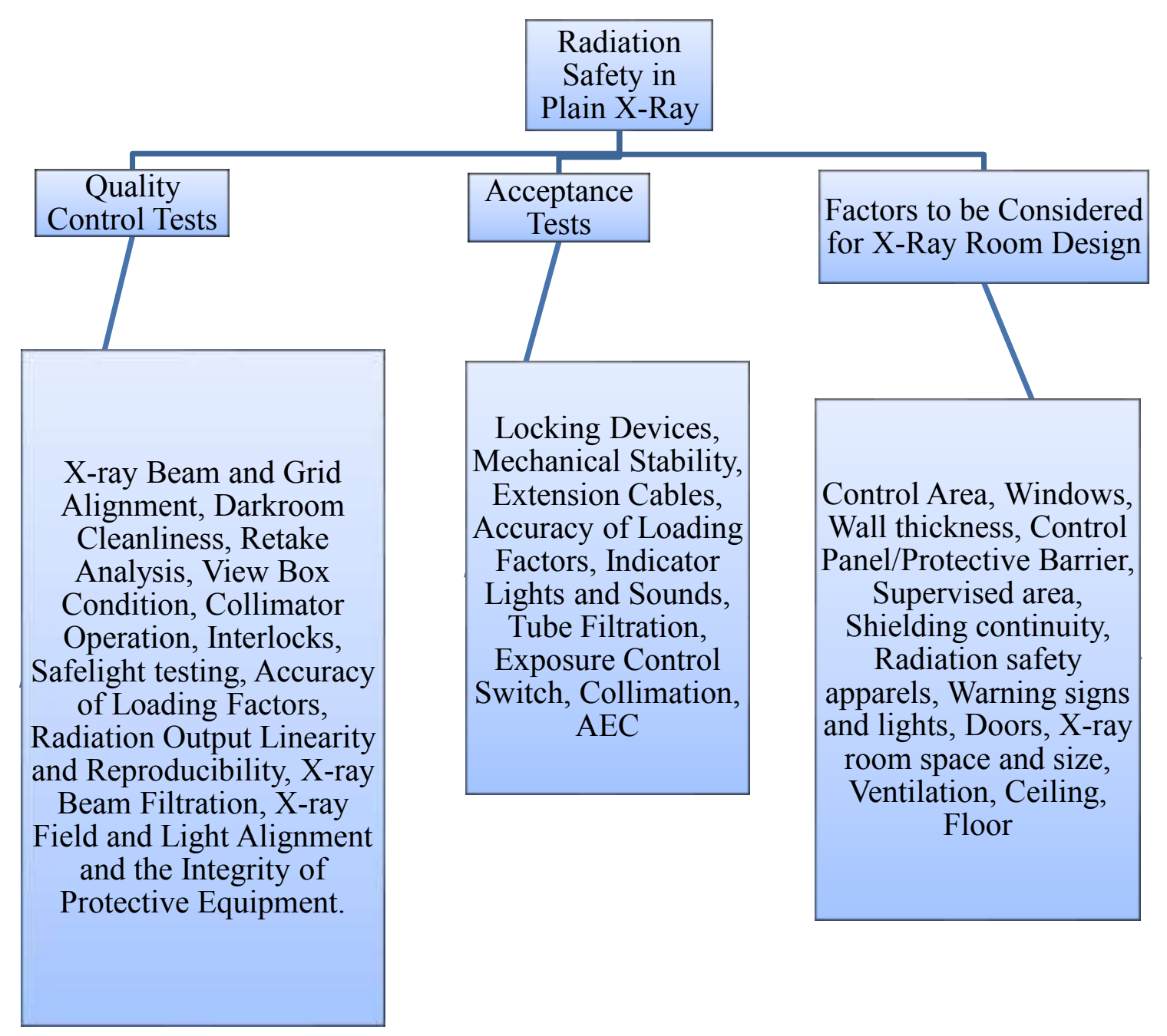

Figure: Radiation Safety in Plain X-Ray. 